\title{
Immunophenotyping invasive breast cancer: paving the road for molecular imaging
}

\author{
Jeroen F Vermeulen ${ }^{1}$, Aram SA van Brussel', Petra van der Groep ${ }^{2}$, Folkert HM Morsink', Peter Bult, \\ Elsken van der Wall ${ }^{2}$ and Paul J van Diest ${ }^{1 *}$
}

\begin{abstract}
Background: Mammographic population screening in The Netherlands has increased the number of breast cancer patients with small and non-palpable breast tumors. Nevertheless, mammography is not ultimately sensitive and specific for distinct subtypes. Molecular imaging with targeted tracers might increase specificity and sensitivity of detection. Because development of new tracers is labor-intensive and costly, we searched for the smallest panel of tumor membrane markers that would allow detection of the wide spectrum of invasive breast cancers.

Methods: Tissue microarrays containing 483 invasive breast cancers were stained by immunohistochemistry for a selected set of membrane proteins known to be expressed in breast cancer.

Results: The combination of highly tumor-specific markers glucose transporter 1 (GLUT1), epidermal growth factor receptor (EGFR), insulin-like growth factor-1 receptor (IGF1-R), human epidermal growth factor receptor 2 (HER2), hepatocyte growth factor receptor (MET), and carbonic anhydrase 9 (CAIX) 'detected' $45.5 \%$ of tumors, especially basal/triple negative and HER2-driven ductal cancers. Addition of markers with a 2-fold tumor-to-normal ratio increased the detection rate to $98 \%$. Including only markers with $>3$ fold tumor-to-normal ratio (CD44v6) resulted in an $80 \%$ detection rate. The detection rate of the panel containing both tumor-specific and less tumor-specific markers was not dependent on age, tumor grade, tumor size, or lymph node status.

Conclusions: In search of the minimal panel of targeted probes needed for the highest possible detection rate, we showed that $80 \%$ of all breast cancers express at least one of a panel of membrane markers (CD44v6, GLUT1, EGFR, HER2, and IGF1-R) that may therefore be suitable for molecular imaging strategies. This study thereby serves as a starting point for further development of a set of antibody-based optical tracers with a high breast cancer detection rate.
\end{abstract}

Keywords: Invasive breast cancer, Tumor markers, Optical imaging, Immunohistochemistry, Antibody panel

\section{Background}

In The Netherlands, the lifetime risk to develop breast cancer increased in the last decades from 1 in 10 in 1989 to 1 in 7 in 2003 [1]. In parallel, the annual number of newly diagnosed cases of breast cancer rose to over 13,000 in 2008 [2]. This makes breast cancer the most commonly diagnosed female cancer in The Netherlands. Despite this increase in incidence, the number of deaths due to breast cancer has remained stable in the last decades, with annually around 3,300 deaths in The

\footnotetext{
* Correspondence: p.j.vandiest@umcutrecht.nl

'Department of Pathology, University Medical Center Utrecht, Utrecht, The Netherlands

Full list of author information is available at the end of the article
}

Netherlands in the period 1989-2008 [3]. Early detection by mammographic population screening has likely contributed to this, leading to diagnosis of smaller, often non-palpable breast cancers and ductal carcinoma in situ (DCIS) lesions [4,5]. Nevertheless, mammography is not optimally sensitive and specific, especially in younger patients and patients with dense breasts [6-11]. Ultrasonography and magnetic resonance imaging (MRI) have been shown to contribute to early detection of breast cancer, as has positron emission tomography (PET) imaging, but these three imaging devices also have their limitations [12].

Molecular optical imaging with near-infrared fluorescent (NIRF) probes holds promise here [13]. First, the spectral properties (emission wavelengths between 700-

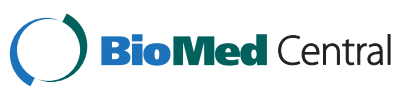


$900 \mathrm{~nm}$ ) of the fluorescent tracers result in low background (auto)fluorescence [14]. Second, the detection can be highly sensitive and specific and third, it enables to detect tumors up to centimeters deep in tissue [15]. Fourth, no protective measures are required since no ionizing radiation is emitted [16], and fifth, NIRF probes can be conjugated to highly specific targeted molecules such as antibodies, antibody fragments, peptides, or protease activatable substrates to increase the specificity of the signal in the tumor as reviewed by Pleijhuis et al. [17].

Several molecular targets have been suggested to be suitable for optical detection of breast cancer such as the epidermal growth factor receptor (EGFR) [18], vascular endothelial growth factor (VEGF) [13,19], and (human epidermal growth factor receptor 2) HER2 $[20,21]$. In addition, hypoxia up-regulated surface antigens like glucose transporter 1 (GLUT1) and carbonic anhydrase 9 (CAIX) that are expressed in about half of invasive breast cancers [22] and also in DCIS [23] and therefore might be valuable targets. Since NIRF antibodies will not be easily internalized, intracellular molecular targets relevant for optical detection of breast cancer have so far been ignored.

However, no single molecular target is expressed in all invasive breast cancers and at the same time provides adequate signal-to-noise ratio to the normal breast. For screening purposes a panel of probes, i.e. antibodies or antibody fragments will likely be necessary. Because development of such antibody-based probes is laborintensive and costly, we set out to screen for expression of a selected set of candidate targets on tissue microarrays containing 483 cases of human invasive breast cancer, in search of the minimum antibody panel that would be suitable for detection of most breast cancers in vivo by molecular imaging.

\section{Methods}

\section{Patients}

The study population was derived from the archives of the Departments of Pathology of the University Medical Center Utrecht, Utrecht, and the Radboud University Nijmegen Medical Centre, Nijmegen, The Netherlands. These comprised 483 cases of invasive breast cancer (operated between 1997 and 2007), of which 340 cases were part of a consecutive series (operated between 2003-2007). The series was enriched with a small consecutive series of lobular breast cancers and a consecutive series of 23 cases with a BRCA germline mutation as previously described [24].

Histological grade was assessed according to the Nottingham scheme [25], and mitotic activity index (MAI) was assessed as before [26]. From representative donor paraffin blocks of the primary tumors, tissue microarrays were constructed by transferring tissue cylinders of $0.6 \mathrm{~mm}$ (3 cylinders per tumor) from the tumor area, determined by a pathologist based on haematoxylineosin stained slides, using a tissue arrayer (Beecher Instruments, Sun Prairie, WI, USA) as described before [27]. Normal breast tissue was obtained from patients that underwent mammoplasty (and thus had no tumor at all). In case of matched tumor and normal tissue, we analyzed normal tissue in paraffin blocks that did not contain any tumor and thus were far away from the tumor. The use of anonymous or coded left over material for scientific purposes is part of the standard treatment contract with patients in The Netherlands [28]. Ethical approval was not required.

\section{Immunohistochemistry}

Immunohistochemistry was carried out on $4 \mu \mathrm{m}$ thick sections for a panel of potential molecular membrane bound targets known to be expressed in a frequency of $>10 \%$ in breast cancer. These were partly highly tumor specific, meaning that they have no or low intensity staining of the normal breast tissue (GLUT1, EGFR, insulin-like growth factor-1 receptor (IGF-1R), HER2, CAIX, hepatocyte growth factor receptor (MET)). We also included less tumor-specific, meaning that are known to have moderate or high intensity staining of the normal breast tissue (Mucin 1 (MUC1), CD44v6, Mammaglobin, transferrin receptor (TfR), carbonic anhydrase 12 (CAXII)), since cancers have usually increased cellularity compared to the normal breast and could thereby also provide adequate signal-to-noise in tumors compared to the normal breast.

After deparaffination and rehydration, endogenous peroxidase activity was blocked for $15 \mathrm{~min}$ in a buffer solution pH5.8 containing $0.3 \%$ hydrogen peroxide. After antigen retrieval, i.e. boiling for $20 \mathrm{~min}$ in $10 \mathrm{mM}$ citrate pH6.0 (for progesterone receptor (PR), CD44v6, GLUT1, CAIX, MET, TfR, and CAXII), Tris/EDTA pH9.0 (estrogen receptor $\alpha(\mathrm{ER} \alpha)$, HER2, IGF1-R, MUC1, and Mammaglobin) or Prot $\mathrm{K}(0.15 \mathrm{mg} / \mathrm{ml})$ for $5 \mathrm{~min}$ at room temperature (EGFR), a cooling off period of $30 \mathrm{~min}$ preceded the primary antibody incubation. CD44v6 (clone VFF18, BMS125 Bender MedSystems, Austria) 1:500; ER $\alpha$ (clone ID5, DAKO, Glostrup Denmark) 1:200; PR (clone PgR636, DAKO) 1:100; HER2 (SP3, Neomarkers, Duiven, The Netherlands) 1:100; GLUT1 (A3536, DAKO) 1:200; CAIX (ab15086, Abcam, Cambridge, UK) 1:1,000; IGF1-R (NB110-87052, Novus Biologicals, Cambridge, UK) 1:400; TfR (13-6800, Invitrogen, Breda, The Netherlands) 1:300; MUC1 (EMA, M1613 clone E29, DAKO) 1:400; Mammaglobin (clone 304-1A5, DAKO) 1:100; CAXII (HPA008773, Sigma Aldrich, Zwijndrecht, The Netherlands) 1:200 were incubated for $1 \mathrm{~h}$ at room temperature. Primary antibodies against EGFR (clone 31 G7, Zymed, 
Invitrogen) 1:30; MET (18-2257, Zymed, Invitrogen) 1:100 were incubated overnight at $4^{\circ} \mathrm{C}$. All primary antibodies were diluted in PBS containing 1\% BSA.

The signal was amplified using Powervision poly-HRP anti-mouse, rabbit, rat (DPVO-HRP, Immunologic, Duiven, The Netherlands) or the Novolink kit (Leica, Rijswijk, The Netherlands) (in the case of EGFR) and developed with diaminobenzidine, followed by counterstaining with haematoxylin, dehydration in alcohol and mounting.

\section{Scoring of immunohistochemistry}

All stainings were compared to normal breast tissue and scored as positive when a clear membranous staining was seen and when the expression in the tumor was clearly higher than in the normal breast tissue. All stainings were scored using the DAKO/HER2 scoring system for membranous staining. Scores $2+$ and $3+$ were considered as positive except for HER2 where only a score of $3+$ was considered positive. Due to the strong intratumor heterogeneity of Mammaglobin expression, scoring was performed by estimating the percentage of positive tumor cells, considering cancers with more than $35 \%$ of the membrane stained tumor cells as positive. All scoring was done by a single experienced pathologist (PJvD) who was blinded to patient characteristics and results of other stainings. To take tumor-heterogeneity between the tumor cores into account, the average score per tumor was calculated and used for analyses. Only in case of GLUT1 and CAIX, the tumor was classified as positive when a single core showed positivity. In this study a maximum of 3 missing stainings per patient was allowed, these stainings were considered as negative in the analyses. This potentially results in underestimation of the percentage positivity of a marker.

Based on ER $\alpha, P R$, and HER2 immunohistochemistry, tumors were classified as luminal (ER $\alpha$ and/or PR positive), HER2-driven (ER $\alpha-$, PR-, HER2+), triple negative (ER $\alpha-$, PR-, HER2-) or basal (ER $\alpha-$, PR-, HER2-, EGFR+), the immunohistochemical surrogate [29] of the original Sorlie/Perou classification [30].

\section{Immunofluorescence for quantification of protein expression in tumor and normal breast tissue}

Several of the evaluated molecular membrane targets (CD44v6, MUC1, TfR, Mammaglobin, and CAXII) are known to be expressed to some extent in the normal breast epithelium. In order for these targets to be useful for breast cancer screening by optical imaging, the signal to background ratio needs to be high enough to be discriminative. We therefore performed immunofluorescence with these antibodies to allow quantification of expression ratios between normal breast and cancer tissue of four randomly selected patients by image analysis.
Immunofluorescence was performed as described above for immunohistochemistry, except that the primary antibodies were detected by incubation with Goat-anti-mouse /rabbit Alexa555 (1:1,000, Invitrogen) for $1 \mathrm{~h}$ at room temperature, followed by 4,6-Diamidine-2-phenylindole dihydrochloride (DAPI) counterstaining and mounting with Immumount (Thermo Scientific, Etten-Leur, The Netherlands).

Representative images of normal breast and breast cancers from the same sections were taken using identical settings at 20x magnification using a Leica DMI4000b inverted bright-field/fluorescence microscope.

\section{Image analysis of tumor expression versus normal breast tissue}

Conventional immunohistochemical slides were digitalized for image analysis using a digital slide scanner (Aperio Technologies Inc., Vista, CA, USA). Of each patient four representative areas of normal and tumor tissue were selected and the average membrane intensity was calculated with the IHC membrane algorithm (Aperio, v8.001). As the signal-to-noise ratio in vivo is determined by the difference in expression between cancer and normal cells as well as by cellularity, the number of cells in the selected area was obtained from the algorithm. Tumor-to-normal ratio was calculated as (membrane intensity*cellularity/area) of the tumor/(membrane intensity*cellularity/area) of normal tissue.

Tumor-to-normal ratios of the fluorescently labeled antibodies were calculated with ImageJ using the median intensity scores. Values are expressed as the average tumor/normal ratio \pm SEM.

Based on experience in radiology with the blood-pool agent indocyanine green in studies assuming a leaky vessel model [31,32], and from studies using NIRF labeled trastuzumab/bevacizumab in mouse models [33], a tumor-to-normal ratio larger than 3 was considered to be sufficient for optical imaging.

\section{Statistics}

Statistical analysis was performed using IBM SPSS Statistics version 18.0 (SPSS Inc., Chicago, IL, USA). Associations between categorical variables were examined using the Pearson's Chi-square test. P-values $<0.05$ were considered to be statistically significant.

\section{Results}

To investigate the most promising combination of markers suitable for imaging, we studied the expression of a panel of membrane markers in our study population that comprised 319 (66.0\%) invasive ductal, 126 (26.1\%) invasive lobular, and 38 (7.9\%) invasive breast cancers with other histology. Other clinicopathological characteristics are shown in Table 1. 
Table 1 Clinicopathological characteristics of 483 invasive breast cancer patients studied for expression of selected membrane markers

\begin{tabular}{|c|c|c|c|}
\hline Feature & Grouping & $\mathrm{N}$ or value & $\%$ \\
\hline \multirow[t]{2}{*}{ Age (years) } & Mean & 60 & \\
\hline & Range & 28 to 88 & \\
\hline \multirow[t]{3}{*}{ Histological type } & Invasive ductal cancer & 319 & 66.0 \\
\hline & Invasive lobular cancer & 126 & 26.1 \\
\hline & Others & 38 & 7.9 \\
\hline \multirow[t]{4}{*}{ Tumor size $(\mathrm{cm})$} & $\leq 2$ & 206 & 42.7 \\
\hline & $>2$ and $\leq 5$ & 219 & 45.3 \\
\hline & $>5$ & 49 & 10.1 \\
\hline & Not available & 9 & 1.9 \\
\hline \multirow[t]{4}{*}{ Histological grade } & 1 & 89 & 18.4 \\
\hline & 2 & 169 & 35.0 \\
\hline & 3 & 219 & 45.4 \\
\hline & Not available & 6 & 1.2 \\
\hline \multirow[t]{3}{*}{ Lymph node status } & Negative ${ }^{*}$ & 225 & 46.6 \\
\hline & Positive ${ }^{* *}$ & 232 & 48.0 \\
\hline & Not available & 26 & 5.4 \\
\hline
\end{tabular}

: negative $=\mathrm{NO}$ or $\mathrm{NO}(\mathrm{i}+) ;{ }^{* *}:$ positive $=\geq \mathrm{N} 1 \mathrm{mi}$ (according to $\mathrm{TNM} 7^{\text {th }}$ edition, 2010).

Representative pictures of immunohistochemistry for the highly tumor-specific molecular membrane targets are shown in Figure 1a. The most widely expressed tumorspecific protein in our cohort was GLUT1, positive in $20.3 \%$ of the cancers, followed by EGFR (17.4\%), IGF-1R (12.8\%), HER2 (10.4\%), CAIX (9.5\%), and MET (8.9\%). The less tumor-specific targets MUC1 (90.7\%), CD44v6 (63.8\%), Mammaglobin (16.8\%), TfR (14.5\%), and CAXII (8.7\%) were in general more frequently expressed than the tumor-specific targets (Table 2). Representative pictures of immunohistochemistry for the less tumor-specific molecular membrane targets are shown in Figure $1 b$.

\section{Detection rate of combinations of highly tumor-specific molecular targets in relation to grade, molecular and histological type}

Because the frequency of expression (further denoted 'detection rate') of individual highly tumor-specific markers did not exceed $20.3 \%$ of the cases, we examined several combinations of markers by sequential addition of markers to the expression of GLUT1, the most widely expressed highly tumor-specific marker. GLUT1 in combination with EGFR resulted in $30.0 \%$ positive cases, GLUT1/IGF1-R in $28.8 \%$, GLUT1/HER2 in $27.7 \%$, GLUT1/MET in 25.2\%, and GLUT1/CAIX in 22.3\% positive cases. The panel GLUT1, EGFR, HER2, IGF1-R, MET, and CAIX resulted in $45.5 \%$ positive cases, although the contribution of CAIX and MET was minimal (Figure 2A).
Clear differences were found between histological subtypes of breast cancer (Table 3). Lobular carcinomas hardly expressed any of the tumor-specific membrane targets present in the panel compared to ductal carcinomas (detection rate $18.3 \%$ vs. $55.5 \%, \mathrm{p}<0.001$ ). Within the group of lobular carcinomas, pleomorphic lobular carcinomas expressed more membrane targets than classical lobular carcinomas (detection rate $26.8 \%$ vs. $8.6 \%$, $\mathrm{p}=0.034$ ). Within the group of ductal carcinomas, the basal/triple negative (TN) and HER2-driven ductal cancers expressed more frequently hypoxia markers or growth factor receptors than luminal-type ductal cancers (detection rate $84.2 \%$ vs. $45.0 \%, \mathrm{p}<0.001$ ) (Table 4). Therefore the panel EGFR, MET, HER2, GLUT1, CAIX, and IGF1-R detected $84.2 \%$ of the basal/TN ductal breast cancers compared to $45.0 \%$ of the luminal-type, and $18.3 \%$ of the lobular breast cancer cases (Figure 2A, Tables 3 and 4). Because the markers included in our panel are associated with an aggressive phenotype and poor prognosis, we evaluated the detection rate of our panel in relation to grade (Figure 2B). Low grade (grade 1) tumors had a detection rate of $22.5 \%$ for this panel, in contrast to $33.7 \%$ of grade 2 and $63.9 \%$ of grade 3 tumors $(\mathrm{p}<0.001)$. This indicates that the panel with tumor-specific antigens is less sensitive for detecting luminal-type, lobular, and low grade/well-differentiated tumors when applied for imaging strategies.

\section{Molecular targets that are expressed in normal breast tissue have sufficient signal-to-noise to detect lobular and luminal-type breast cancer}

Since lobular and luminal-types of breast cancer appeared to hardly express tumor-specific antigens, antigens that are less tumor-specific are required for their detection. Like with tumor-specific markers, variation between histological and molecular subtypes was observed for TfR, Mammaglobin, and CAXII. Luminal-type ductal cancers and lobular cancers expressed significantly more CAXII $(10.5 \%$ vs. $2.3 \%, \mathrm{p}=0.017)$ and Mammaglobin $(19.9 \%$ vs. $5.9 \%, \mathrm{p}=0.002)$ compared to HER2-driven and basal/TN ductal cancers (Tables 3 and 4). TfR expression in lobular and luminal type ductal cancers was significantly lower than in HER2-driven and basal/TN cancers $(11.9 \%$ vs. $27.9 \%, \mathrm{p}<0.001$ ). For MUC1 and CD44v6, no differences in expression were found between lobular and ductal cancer (Tables 3 and 4).

Due to the expression of less tumor-specific antigens in the normal breast epithelium (Figure 1B), the signalto-noise ratio (or tumor-to-normal) needs to be sufficiently discriminating to be applicable for imaging strategies. We determined therefore the tumor-to-normal ratio in a quantitative manner by image analysis of digital slides, considering a 3-fold tumor-to-normal ratio as sufficient. Image quantification using conventional IHC showed 


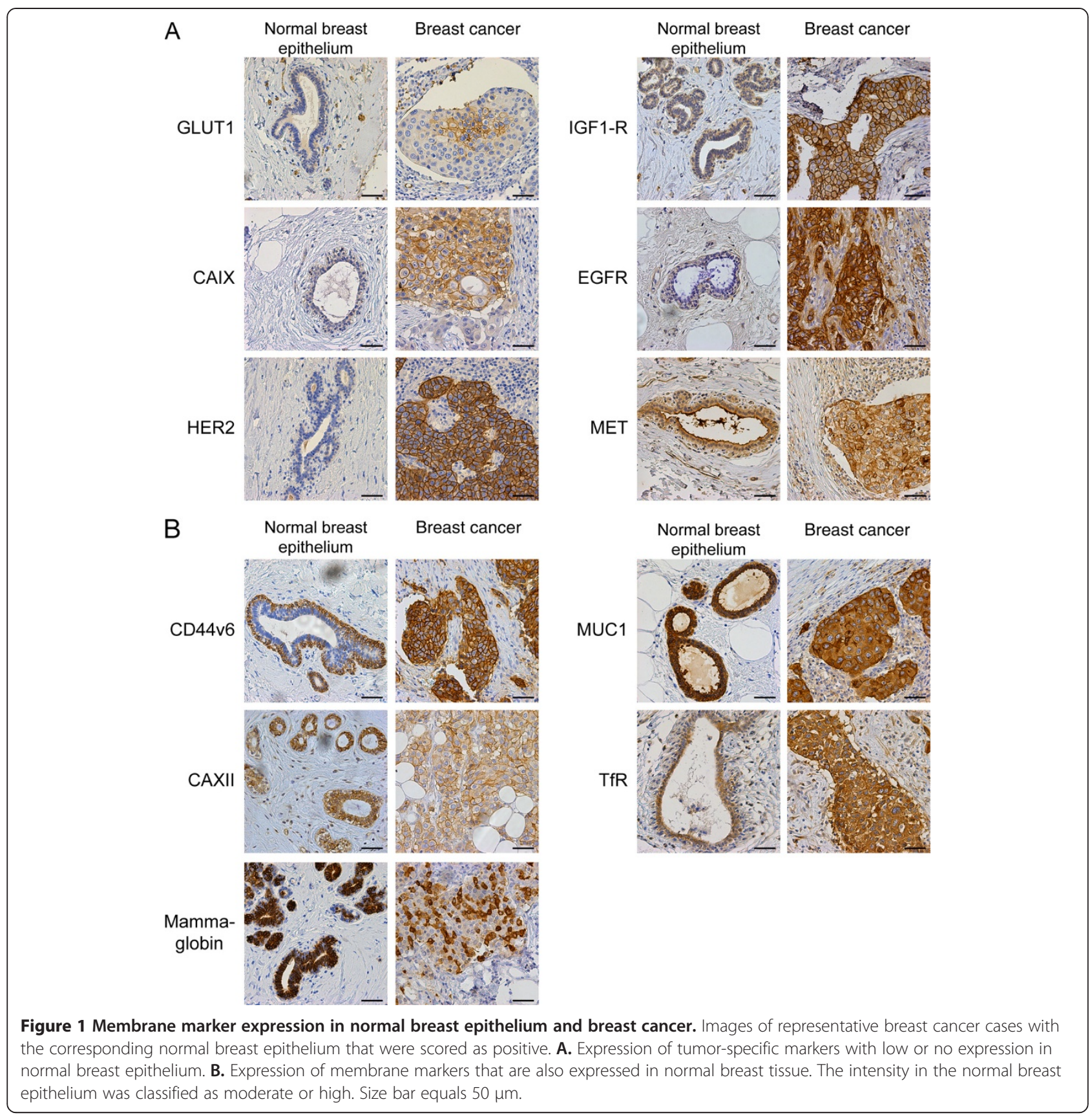

that the intensity of the staining was dependent on the cellularity of the tumor as expected. This resulted in tumorto-normal ratios of $4.8 \pm 0.56,2.3 \pm 0.27,1.2 \pm 0.095$, $4.6 \pm 0.62$, and $2.4 \pm 0.88$ for CD44v6, MUC1, Mammaglobin, CAXII, and TfR, respectively.

Since conventional immunohistochemistry is not necessarily quantitative, we also performed immunofluorescence using directly fluorescently labeled antibodies. The results were comparable with conventional immunohistochemistry (Figure 3) resulting in tumor-tonormal ratios of $3.93 \pm 0.14,2.74 \pm 0.46,1.54 \pm 0.11$, and
$1.66 \pm 0.066$ for CD44v6, MUC1, Mammaglobin, and CAXII, respectively. TfR expression was not detectable using immunofluorescence. Thereby, CD44v6 was the only less tumor-specific marker consistently meeting the required 3-fold tumor-to-normal ratio.

\section{Detection rate of combined highly and less tumor-specific molecular targets}

Including TfR, Mammaglobin, and MUC1 to the panel of highly tumor-specific markers GLUT1, MET, EGFR, IGF1-R, CAIX, and HER2 increased the detection rate 
Table 2 Frequency of expression by immunohistochemistry of tumor-specific and less tumorspecific membrane markers in breast cancers

\begin{tabular}{|c|c|c|c|c|c|c|}
\hline \multirow[t]{2}{*}{ Target } & \multicolumn{2}{|c|}{ Positive } & \multicolumn{2}{|c|}{ Negative } & \multicolumn{2}{|c|}{ Missing } \\
\hline & $\mathrm{N}$ & $\%$ & $\mathrm{~N}$ & $\%$ & $\mathbf{N}$ & $\%$ \\
\hline HER2 & 50 & 10.4 & 432 & 89.4 & 1 & 0.2 \\
\hline EGFR & 84 & 17.4 & 395 & 81.8 & 4 & 0.8 \\
\hline MET & 43 & 8.9 & 423 & 87.6 & 17 & 3.5 \\
\hline IGF1-R & 62 & 12.8 & 400 & 82.8 & 21 & 4.3 \\
\hline GLUT1 & 98 & 20.3 & 360 & 74.5 & 25 & 5.2 \\
\hline CAIX & 46 & 9.5 & 414 & 85.3 & 25 & 5.2 \\
\hline TfR & 70 & 14.5 & 402 & 83.2 & 11 & 2.3 \\
\hline CD44v6 & 308 & 63.8 & 160 & 33.1 & 15 & 3.1 \\
\hline CAXII & 42 & 8.7 & 426 & 88.2 & 15 & 3.1 \\
\hline Mammaglobin & 81 & 16.8 & 382 & 79.1 & 20 & 4.1 \\
\hline MUC1 & 438 & 90.7 & 26 & 5.4 & 19 & 3.9 \\
\hline
\end{tabular}

from $45.5 \%$ to $49.8 \%$ (TfR), $56.4 \%$ (Mammaglobin), and 98.1\% (MUC1), respectively. However, of these markers, only CD44v6 reached a sufficiently high tumor-to-normal ratio (see above), so adding CD44v6 to the panel of highly specific markers therefore realistically increased the overall detection rate to $80.1 \%$. When CD44v6 was included, removal of CAIX or MET from the panel had no influence on the detection rate.

Especially the luminal-type ductal and lobular breast cancers were better detected by including CD44v6. Upon addition of CD44v6, the detection rate rose from $45.5 \%$ to $78.9 \%$ for luminal-type cancers, from $18.3 \%$ to $72.2 \%$ for the lobular breast cancers, and from $84.2 \%$ to $90.0 \%$ for basal/TN ductal breast cancers (Figure 4A). Moreover, the detection rate of the panel was not dependent on grade $(76.4 \%, 74.0 \%$, and $84.5 \%$ for grade 1 , grade 2 , and grade 3 tumors, respectively), tumor size
Table 3 Expression of a panel of membrane markers in various histological types of breast cancer

\begin{tabular}{|c|c|c|c|c|c|c|}
\hline \multirow[t]{2}{*}{ Target } & \multicolumn{2}{|c|}{$\begin{array}{c}\text { Ductal } \\
\text { (319 cases) }\end{array}$} & \multicolumn{2}{|c|}{$\begin{array}{l}\text { Lobular } \\
\text { (126 cases) }\end{array}$} & \multicolumn{2}{|c|}{$\begin{array}{c}\text { Other } \\
\text { (38 cases) }\end{array}$} \\
\hline & $\mathrm{N}$ & $\%$ & $\mathrm{~N}$ & $\%$ & $\mathrm{~N}$ & $\%$ \\
\hline HER2 & 43 & 13.5 & 4 & 3.2 & 3 & 7.9 \\
\hline EGFR & 71 & 22.3 & 4 & 3.2 & 9 & 23.7 \\
\hline MET & 34 & 10.7 & 4 & 3.2 & 5 & 13.2 \\
\hline IGF1-R & 48 & 15.0 & 7 & 5.6 & 7 & 18.4 \\
\hline GLUT1 & 85 & 26.6 & 5 & 4.0 & 8 & 21.1 \\
\hline CAIX & 38 & 11.9 & 2 & 1.6 & 6 & 15.8 \\
\hline TfR & 53 & 16.6 & 10 & 7.9 & 7 & 18.4 \\
\hline CD44v6 & 197 & 61.8 & 82 & 65.1 & 29 & 76.3 \\
\hline CAXII & 30 & 9.4 & 12 & 9.5 & 1 & 2.6 \\
\hline Mammaglobin & 44 & 13.8 & 34 & 27.0 & 3 & 7.9 \\
\hline MUC1 & 218 & 88.1 & 119 & 94.4 & 38 & 100 \\
\hline
\end{tabular}

(79.1\%, $77.6 \%$, and $85.7 \%$ for tumors $\leq 2 \mathrm{~cm},>2$ and $\leq 5 \mathrm{~cm}$, and $>5 \mathrm{~cm}$, respectively), lymph node status (76.2\% for lymph node negative, and $82.7 \%$ for lymph node positive cases), or age ( $78.8 \%$ for patients $<60$ years and $80.1 \%$ for patients $>60$ years) (Figure $4 \mathrm{~B}$ ).

Therefore, the optimal combination of membraneexpressed proteins to target by molecular imaging seemed to consist of CD44v6, GLUT1, EGFR, HER2, and IGF1-R by which about $80 \%$ of invasive breast cancers are predicted to be detectable.

\section{Discussion}

The aim of this study was to identify the minimum panel of membrane markers that may be suitable for detection of invasive breast cancer by molecular imaging. In order to determine this combination, we stained TMAs consisting of 483 clinical specimens of invasive breast
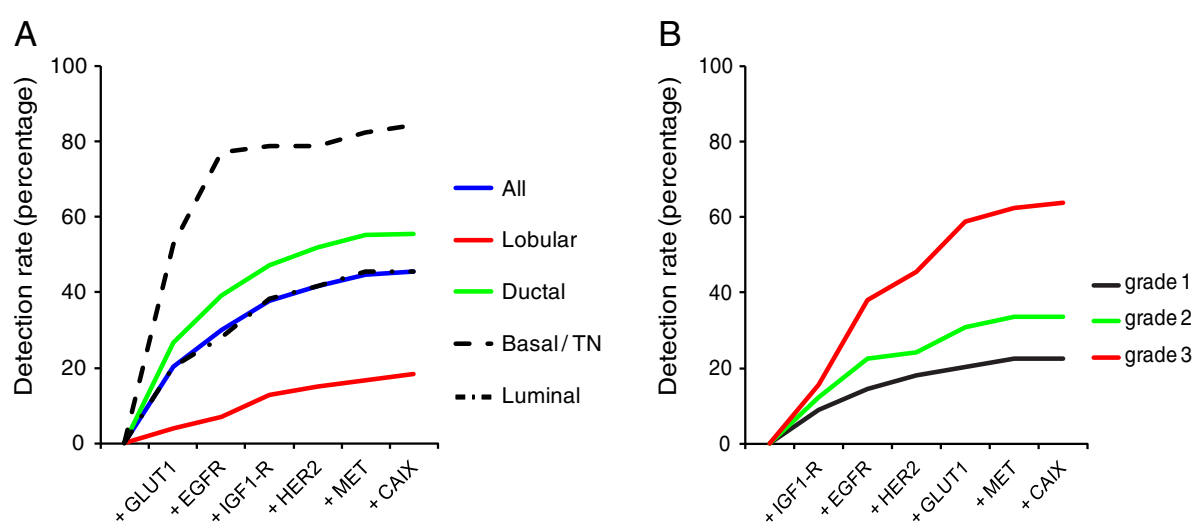

Figure 2 Detection rate of tumor-specific membrane markers for detection of breast cancer. Detection rate of highly tumor-specific membrane markers for detecting luminal, HER2-driven, basal/triple negative ductal breast cancers, and lobular breast cancers. The detection rate of tumor-specific markers for detection of breast cancer plotted as the positivity of the marker in combination with all preceding markers. 
Table 4 Expression of membrane markers in molecular subtypes of ductal breast cancer

\begin{tabular}{|c|c|c|c|c|c|c|}
\hline \multirow[t]{2}{*}{ Target } & \multicolumn{2}{|c|}{$\begin{array}{l}\text { Luminal } \\
\text { (242 cases) }\end{array}$} & \multicolumn{2}{|c|}{$\begin{array}{l}\text { HER2-driven } \\
\text { ( } 20 \text { cases) }\end{array}$} & \multicolumn{2}{|c|}{$\begin{array}{c}\text { Basal/TN } \\
\text { (57 cases) }\end{array}$} \\
\hline & $\mathrm{N}$ & $\%$ & $\mathbf{N}$ & $\%$ & $\mathrm{~N}$ & $\%$ \\
\hline HER2 & 23 & 9.5 & 20 & 100 & 0 & 0.0 \\
\hline EGFR & 25 & 10.3 & 11 & 55 & 35 & 61.4 \\
\hline MET & 21 & 8.7 & 4 & 20 & 9 & 15.8 \\
\hline IGF1-R & 41 & 16.9 & 2 & 10 & 5 & 8.8 \\
\hline GLUT1 & 49 & 20.2 & 6 & 30 & 30 & 52.6 \\
\hline CAIX & 11 & 4.5 & 4 & 20 & 23 & 40.4 \\
\hline TfR & 33 & 13.6 & 5 & 25 & 40 & 70.2 \\
\hline CD44v6 & 148 & 61.8 & 9 & 45 & 15 & 26.3 \\
\hline CAXII & 28 & 11.6 & 1 & 5 & 1 & 1.8 \\
\hline Mammaglobin & 39 & 16.1 & 4 & 20 & 1 & 1.8 \\
\hline MUC1 & 213 & 88.0 & 20 & 100 & 48 & 84.2 \\
\hline
\end{tabular}

cancer by immunohistochemistry. Based on the expression profiles in the normal breast tissue, we defined highly tumor-specific (no or low staining of the normal breast tissue) and less tumor-specific (moderate or high staining of the normal breast tissue) membrane targets. We found that the expression of highly tumor-specific targets (HER2, EGFR, GLUT1, CAIX, IGF1-R, and MET) is quite dependent on the tumor histology and molecular subtype: ductal cancers and in particular the basal/TN and HER2-driven subtypes express more frequently highly tumor-specific membrane targets than lobular cancers.

Because the individual tumor-specific markers are clearly not sensitive enough, application of a tumorspecific panel of tracers is required to detect all types of breast cancer. A panel of tumor-specific markers (GLUT1, EGFR, HER2, IGF1-R, MET, and CAIX) was in the present study able to 'detect' $45.5 \%$ of all cancers and $55.6 \%$ of ductal cancers. For lobular cancers and low-grade tumors, the panel was not very suitable because with detection rates of $18.3 \%$ and $22.5 \%$, respectively. Addition of less tumor-specific markers theoretically increased the detection rate to $98.1 \%$ using MUC1, but of the less tumor specific markers only CD44v6 met the desired 3-fold tumor-to-normal tissue ratio measured by image analysis. When adding CD44v6 to the panel, $80.1 \%$ of all cancers could be 'detected' with

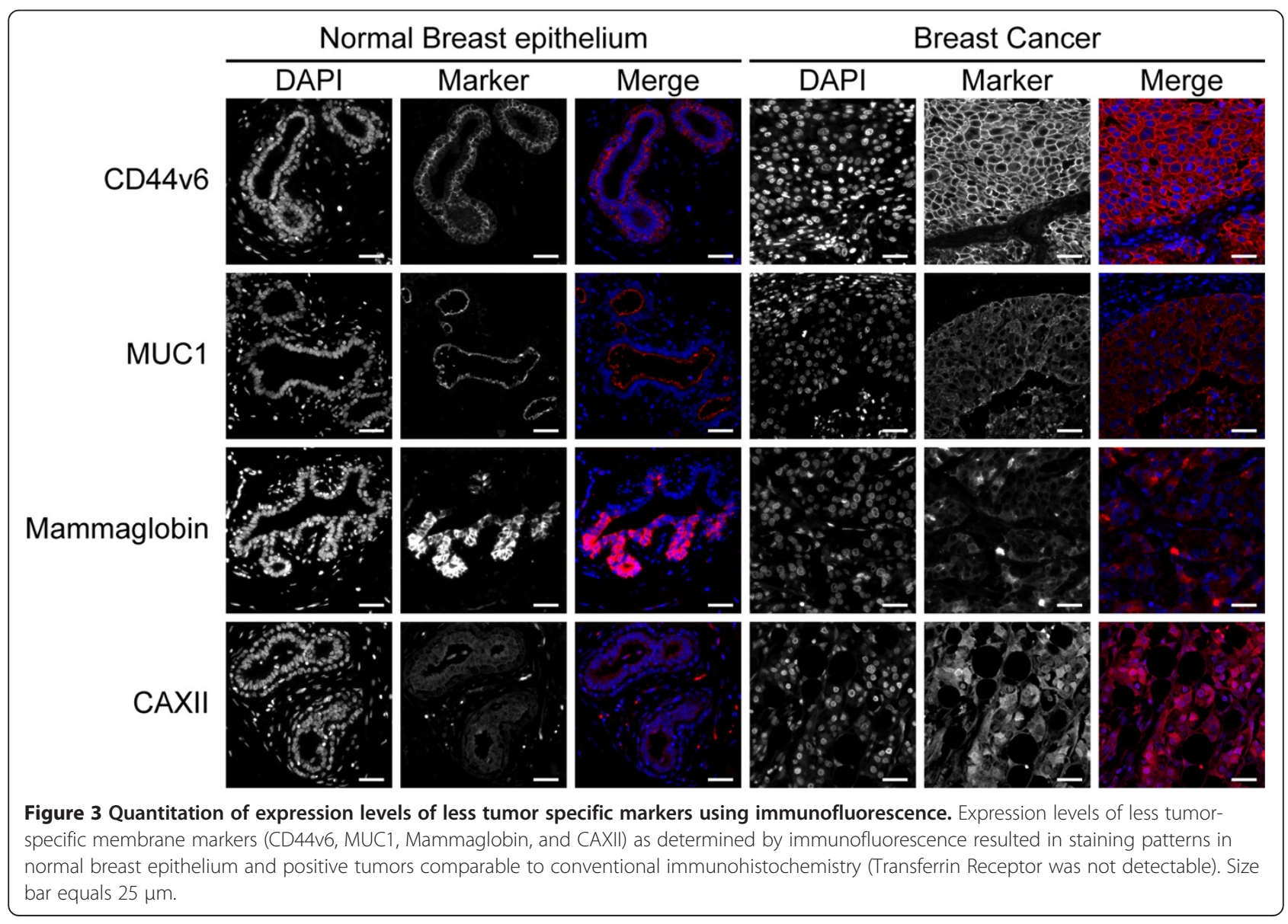



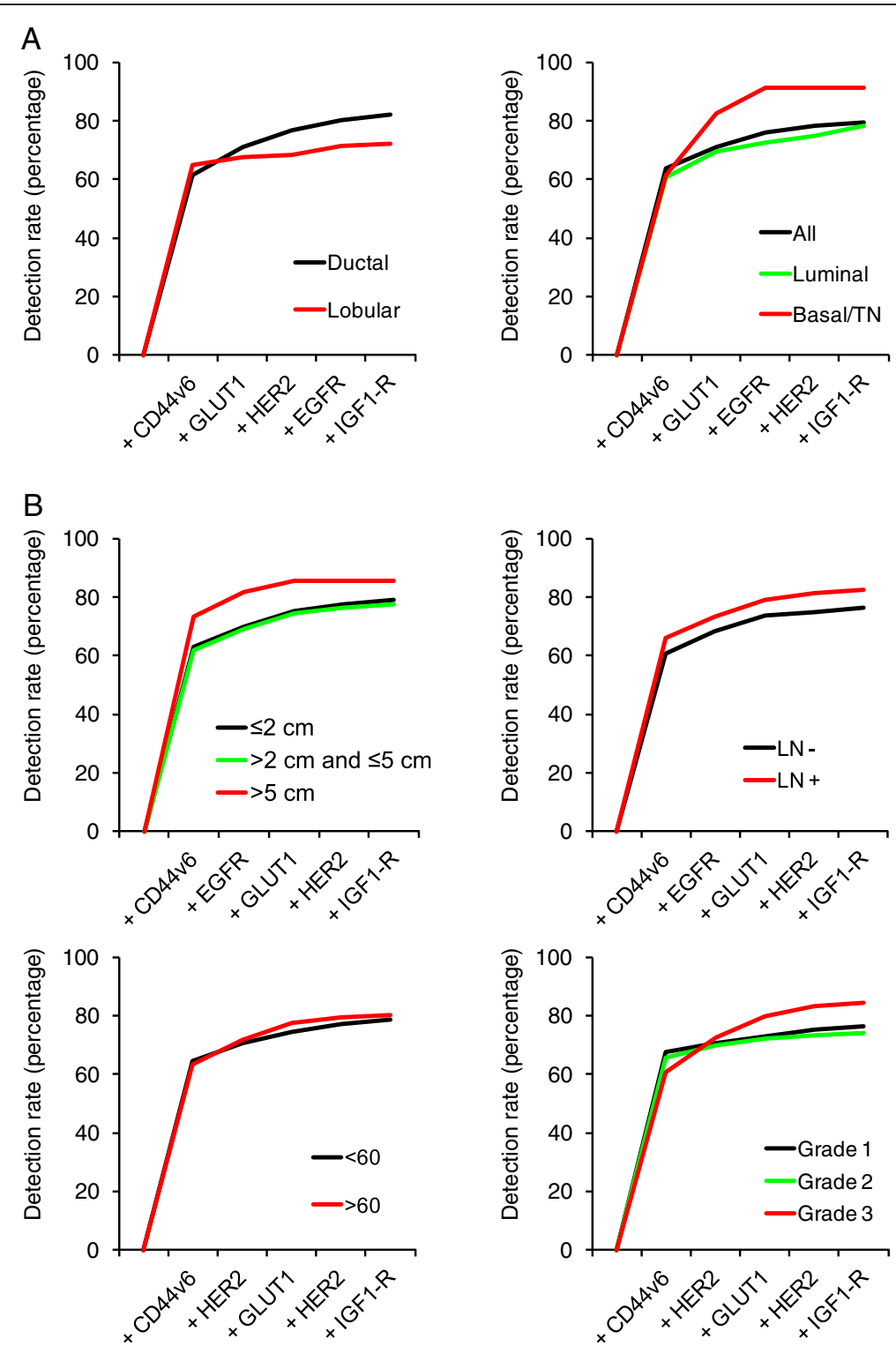

Figure 4 Optimal combination of membrane markers for detection of breast cancer correlated with clincopathological characteristics. A. The contribution of each tumor-specific and less tumor-specific membrane marker in the optimal panel for detection of breast cancer. B. The detection rate of the panel with respect to several clinicopathological features.

at least one marker in a panel consisting of HER2, GLUT1, EGFR, IGF1-R, and CD44v6. CAIX and MET had no additional effect on the sensitivity of the panel once CD44v6 had been included.

Our estimation of positivity of breast cancers for our panel may have been conservative since we have been very stringent in calling expression positive, explaining why our rates of expression for GLUT1, CAIX, EGFR, MET, TfR, CAXII, and Mammaglobin are on the lower side compared to the literature [22,34-43]. Tumors with $1+$ membrane staining were consistently considered negative as we expect that this level of staining provides insufficient signal-to-noise, but only in vivo studies can confirm this. Moreover, quantification of expression levels based on image analysis of immunohistochemical stainings may be hampered by the non-linear amplification of the signal during immunohistochemistry. For that reason we applied immunofluorescence of directly labeled antibodies for more reliable quantitation of protein expression. Tumor-to-normal ratios above 3 where only obtained when tumors are scored as DAKO $2+$ or $3+$ membranous staining. This justifies the predefined thresholds for calling tumors positive. Furthermore, cytoplasmic staining was ignored as imaging antibodies will not be easily internalized and will have to bind to receptors on the outside of the cancer cells. Lastly, using 
TMAs may have resulted in slight underestimation of GLUT1 and CAIX expression, because the expression is usually limited to hypoxic areas within the tumor $[44,45]$.

Adding further candidate tumor markers may enable to improve the results of our panel of membrane related markers. For instance, biomarkers that are specifically expressed in the stroma of breast cancers like growth factors (e.g. VEGF) may be valuable.

This study provides information on the expression levels of membrane bound targets for imaging using paraffin embedded material of invasive breast cancers. To be suitable for breast cancer detection or screening, multiple steps have to be taken before tracer development and testing in (pre)clinical trials results in treatment of patients. However, the present study elucidates which targets might be most suitable based on the expression in cancer vs. normal breast tissue. One of the current challenges is specific detection of lobular breast cancers and DCIS, because these lesions are difficult to detect by mammography. DCIS was beyond the scope of the current paper, but for detection of lobular breast cancer CD44v6 is potentially quite useful.

Next to expression of target proteins, tumor perfusion and penetration of the tracer into the tumor could influence the signal for imaging. Further, affinity after labeling and half-life of the tracer in the human body determine the tumor-to-background ratio and thus the applicability of a tracer in a clinical setting. Based on preclinical studies using NIRF labeled trastuzumab and bevacizumab, the maximal tumor-to-background ratio was obtained 6 days post injection [33]. Optimizing this by reducing the half-life of the tracer would be beneficial for clinical practice.

The present study underlines that no single membrane marker probe is likely to detect all breast cancers by molecular imaging, and that a panel of least five probes may be required. So far, experience is however limited to maximally two different tracers at once. Barrett et al. [46] showed that two antibodies allowed to identify differences in tumor expression of HER2 and EGFR in vivo. When aiming to be just discriminative between tumor and normal, a panel of markers can be injected with the same probe attached to simplify imaging. Feasibility and toxicity of injecting a panel of markers require further in vivo experiments in mouse models.

\section{Conclusions}

We studied which tumor membrane markers are most discriminating between invasive breast cancer and normal breast tissue in order to identify the minimal number of targeted probes needed for the highest possible breast cancer detection rate. We showed that $80 \%$ of all breast cancers express at least one of a panel of markers
(CD44v6, GLUT1, EGFR, HER2, and IGF1-R) that therefore may be suitable for molecular imaging strategies. The present study thereby serves as a starting point for further development of a set of antibody-based optical tracers with high potential for detecting breast cancer.

\section{Competing interest}

The authors declare that they have no competing interest.

\section{Authors' contributions}

JFV, ASAvB, PvdG, and FHMM performed the experiments. PB and PJVD provided the study material, analyzed and interpreted tumor pathology. PvdG, PB, EvdW, and PJvD critically reviewed the experiments and paper. JFV, $A S A v B$, and PJVD wrote the manuscript. All authors critically reviewed the report and approved the final version of the report for submission. The corresponding author (PJVD) had access to the primary data, took responsibility for accuracy and completeness of data reporting, and had final responsibility for the decision to submit for publication. All authors read and approved the final manuscript.

\section{Acknowledgements}

This work was supported by an unrestricted research grant of AEGON Inc. and by the MAMmary carcinoma MOlecular imaging for diagnostics and THerapeutics (MAMMOTH) project of the Dutch Center for Translational Molecular Medicine.

\section{Author details}

'Department of Pathology, University Medical Center Utrecht, Utrecht, The Netherlands. ${ }^{2}$ Division of Internal Medicine and Dermatology, University Medical Center Utrecht, Utrecht, The Netherlands. 'Department of Pathology, Radboud University Nijmegen Medical Centre, Nijmegen, The Netherlands.

Received: 6 January 2012 Accepted: 31 May 2012

Published: 13 June 2012

\section{References}

1. Paap E, Broeders MJ, van Schoor G, Otten JD, Verbeek AL: Large increase in a Dutch woman's lifetime risk of developing breast cancer. Eur J Cancer 2008, 44:1485-1487.

2. Incidentie van invasive tumoren naar geslacht en lokalisatie per incidentiejaar (1989-2008). [http://www.ikcnet.nl/page.php?id=2902\&nav_id=114].

3. Sterfte aan kanker naar geslacht en lokalisatie en jaar van overlijden (19892008). http://www.ikcnet.nl/uploaded/docs/Landelijk/cijfers/incidentie\% 202008/B1_NL.xls.

4. Medina-Franco H, Abarca-Perez L, Garcia-Alvarez MN, Ulloa-Gomez JL, Romero-Trejo C, Sepulveda-Mendez J: Radioguided occult lesion localization (ROLL) versus wire-guided lumpectomy for non-palpable breast lesions: a randomized prospective evaluation. J Surg Oncol 2008, 97:108-111.

5. Singletary SE: Surgical margins in patients with early-stage breast cancer treated with breast conservation therapy. Am J Surg 2002, 184:383-393.

6. Brown ML, Houn F, Sickles EA, Kessler LG: Screening mammography in community practice: positive predictive value of abnormal findings and yield of follow-up diagnostic procedures. Am J Roentgenol 1995, 165:1373-1377.

7. Elmore JG, Armstrong K, Lehman CD, Fletcher SW: Screening for breast cancer. JAMA 2005, 293:1245-1256.

8. Kerlikowske K, Grady D, Barclay J, Sickles EA, Eaton A, Ernster V: Positive predictive value of screening mammography by age and family history of breast cancer. JAMA 1993, 270:2444-2450.

9. Lidbrink E, Elfving J, Frisell J, Jonsson E: Neglected aspects of false positive findings of mammography in breast cancer screening: analysis of false positive cases from the Stockholm trial. BMJ 1996, 312:273-276.

10. Moadel RM: Breast cancer imaging devices. Semin NuCl Med 2011, 41:229-241.

11. Brewer NT, Salz T, Lillie SE: Systematic review: the long-term effects of false-positive mammograms. Ann Intern Med 2007, 146:502-510.

12. Bos R, van der Hoeven JJ, van der Wall E, van der Groep P, van Diest PJ, Comans EF, Joshi U, Semenza GL, Hoekstra OS, Lammertsma AA, Molthoff CF: Biologic correlates of (18)fluorodeoxyglucose uptake in human 
breast cancer measured by positron emission tomography. J Clin Oncol 2002, 20:379-387.

13. Oude Munnink TH, Nagengast WB, Brouwers AH, Schroder CP, Hospers GA Lub-de Hooge MN, Van der Wall E, van Diest PJ, Vries EG: Molecular imaging of breast cancer. Breast 2009, 18(Suppl 3):S66-S73.

14. Frangioni JV: In vivo near-infrared fluorescence imaging. Curr Opin Chem Biol 2003, 7:626-634.

15. Frangioni JV: New technologies for human cancer imaging. J Clin Oncol 2008, 26:4012-4021.

16. Ntziachristos V: Fluorescence molecular imaging. Annu Rev Biomed Eng 2006, 8:1-33.

17. Pleijhuis RG, Graafland M, de Vries J, Bart J, de Jong JS, van Dam GM: Obtaining adequate surgical margins in breast-conserving therapy for patients with early-stage breast cancer: current modalities and future directions. Ann Surg Oncol 2009, 16:2717-2730.

18. Sampath L, Kwon S, Ke S, Wang W, Schiff R, Mawad ME, Sevick-Muraca EM: Dual-labeled trastuzumab-based imaging agent for the detection of human epidermal growth factor receptor 2 overexpression in breast cancer. J Nucl Med 2007, 48:1501-1510.

19. Viacava $P$, Naccarato AG, Bocci G, Fanelli G, Aretini P, Lonobile A, Evangelista G, Montruccoli G, Bevilacqua G: Angiogenesis and VEGF expression in pre-invasive lesions of the human breast. J Pathol 2004, 204:140-146.

20. Gee MS, Upadhyay R, Bergquist $H$, Alencar $H$, Reynolds F, Maricevich M, Weissleder R, Josephson L, Mahmood U: Human breast cancer tumor models: molecular imaging of drug susceptibility and dosing during HER2/neu-targeted therapy. Radiology 2008, 248:925-935.

21. Lee SB, Hassan M, Fisher R, Chertov O, Chernomordik V, Kramer-Marek G, Gandjbakhche A, Capala J: Affibody molecules for in vivo characterization of HER2-positive tumors by near-infrared imaging. Clin Cancer Res 2008, 14:3840-3849.

22. Bos R, van der Groep P, Greijer AE, Shvarts A, Meijer S, Pinedo HM, Semenza $G L$, van Diest PJ, van der Wall E: Levels of hypoxia-inducible factor-1alpha independently predict prognosis in patients with lymph node negative breast carcinoma. Cancer 2003, 97:1573-1581.

23. Bos $R$, Zhong $H$, Hanrahan CF, Mommers EC, Semenza GL, Pinedo HM, Abeloff MD, Simons JW, van Diest PJ, van der Wall E: Levels of hypoxiainducible factor-1 alpha during breast carcinogenesis. J Natl Cancer Inst 2001, 93:309-314.

24. van der Groep P, Bouter A, van der Zanden R, Menko FH, Buerger H, Verheijen $\mathrm{RH}$, van der Wall E, van Diest PJ: Re: Germline BRCA1 mutations and a basal epithelial phenotype in breast cancer. J Natl Cancer Inst 2004 96:712-713. author reply 714

25. Elston CW, Ellis IO: Pathological prognostic factors in breast cancer. I. The value of histological grade in breast cancer: experience from a large study with long-term follow-up. Histopathology 1991, 19:403-410.

26. van der Groep P, Bouter A, van der Zanden R, Siccama I, Menko FH, Gille JJ, van Kalken $C$, van der Wall E, Verheijen $\mathrm{RH}$, van Diest PJ: Distinction between hereditary and sporadic breast cancer on the basis of clinicopathological data. J Clin Pathol 2006, 59:611-617.

27. Packeisen J, Korsching $E_{1}$ Herbst $H$, Boecker W, Buerger $H$ : Demystified. . .tissue microarray technology. Mol Pathol 2003, 56:198-204.

28. van Diest PJ: No consent should be needed for using leftover body material for scientific purposes. For. BMJ 2002, 325:648-651.

29. Kornegoor R, Verschuur-Maes AH, Buerger $H$, Hogenes MC, de Bruin PC, Oudejans JJ, van der Groep P, Hinrichs B, van Diest PJ: Molecular subtyping of male breast cancer by immunohistochemistry. Mod Pathol 2012, 25:398-404.

30. Sorlie T, Perou CM, Tibshirani R, Aas T, Geisler S, Johnsen H, Hastie T, Eisen $M B$, van de Rijn M, Jeffrey SS, et al: Gene expression patterns of breast carcinomas distinguish tumor subclasses with clinical implications. Proc Natl Acad Sci U S A 2001, 98:10869-10874.

31. Corlu A, Choe R, Durduran T, Rosen MA, Schweiger M, Arridge SR, Schnall MD, Yodh AG: Three-dimensional in vivo fluorescence diffuse optical tomography of breast cancer in humans. Opt Express 2007, 15:6696-6716.

32. van de Ven S, Wiethoff A, Nielsen T, Brendel B, van der Voort M, Nachabe R, van der Mark M, van Beek M, Bakker $L$, Fels $L$, et al: A novel fluorescent imaging agent for diffuse optical tomography of the breast: first clinical experience in patients. Mol Imaging Biol 2010, 12:343-348.

33. van Scheltinga AG Terwisscha, van Dam GM, Nagengast WB, Ntziachristos V, Hollema H, Herek JL, Schroder CP, Kosterink JG, Lub-de
Hoog MN, de Vries EG: Intraoperative near-infrared fluorescence tumor imaging with vascular endothelial growth factor and human epidermal growth factor receptor 2 targeting antibodies. J NuCl Med 2011, 52:1778-1785.

34. Afify A, McNiel MA, Braggin J, Bailey H, Paulino AF: Expression of CD44s, CD44v6, and hyaluronan across the spectrum of normal-hyperplasiacarcinoma in breast. Appl Immunohistochem Mol Morphol 2008, 16:121-127.

35. Bhargava R, Beriwal S, Dabbs DJ: Mammaglobin vs GCDFP-15: an immunohistologic validation survey for sensitivity and specificity. Am J Clin Pathol 2007, 127:103-113.

36. Carracedo A, Egervari K, Salido M, Rojo F, Corominas JM, Arumi M, Corzo C, Tusquets I, Espinet B, Rovira A, et al: FISH and immunohistochemical status of the hepatocyte growth factor receptor (c-Met) in 184 invasive breast tumors. Breast Cancer Res 2009, 11:402.

37. Habashy HO, Powe DG, Staka CM, Rakha EA, Ball G, Green AR, Aleskandarany M, Paish EC, Douglas Macmillan R, Nicholson Rl, et al: Transferrin receptor (CD71) is a marker of poor prognosis in breast cancer and can predict response to tamoxifen. Breast Cancer Res Treat 2010, 119:283-293.

38. Klijn JG, Berns PM, Schmitz PI, Foekens JA: The clinical significance of epidermal growth factor receptor (EGF-R) in human breast cancer: a review on 5232 patients. Endocr Rev 1992, 13:3-17.

39. Lacunza E, Baudis M, Colussi AG, Segal-Eiras A, Croce MV, Abba MC: MUC oncogene amplification correlates with protein overexpression in invasive breast carcinoma cells. Cancer Genet Cytogenet 2010, 201:102-110.

40. Sasaki E, Tsunoda N, Hatanaka Y, Mori N, Iwata H, Yatabe Y: Breast-specific expression of MGB1/mammaglobin: an examination of 480 tumors from various organs and clinicopathological analysis of MGB1-positive breast cancers. Mod Pathol 2007, 20:208-214.

41. Tafreshi NK, Enkemann SA, Bui MM, Lloyd MC, Abrahams D, Huynh AS, Kim J, Grobmyer SR, Carter WB, Vagner J, et al: A mammaglobin-A targeting agent for noninvasive detection of breast cancer metastasis in lymph nodes. Cancer Res 2011, 71:1050-1059.

42. Watson PH, Chia SK, Wykoff CC, Han C, Leek RD, Sly WS, Gatter KC, Ratcliffe $P$, Harris AL: Carbonic anhydrase XII is a marker of good prognosis in invasive breast carcinoma. Br J Cancer 2003, 88:1065-1070.

43. Wykoff CC, Beasley N, Watson PH, Campo L, Chia SK, English R, Pastorek J, Sly WS, Ratcliffe P, Harris AL: Expression of the hypoxia-inducible and tumor-associated carbonic anhydrases in ductal carcinoma in situ of the breast. Am J Pathol 2001, 158:1011-1019.

44. van Diest PJ, Vleugel MM, van der Groep P, van der Wall E: VEGF-D and HIF-1alpha in breast cancer. J Clin Pathol 2005, 58:335. author reply 336

45. van Diest PJ, Vleugel MM, van der Wall E: Expression of HIF-1alpha in human tumours. J Clin Pathol 2005, 58:335-336

46. Barrett $T$, Koyama Y, Hama Y, Ravizzini G, Shin IS, Jang BS, Paik CH, Urano Y Choyke PL, Kobayashi H: In vivo diagnosis of epidermal growth factor receptor expression using molecular imaging with a cocktail of optically labeled monoclonal antibodies. Clin Cancer Res 2007, 13:6639-6648.

\section{doi:10.1186/1471-2407-12-240}

Cite this article as: Vermeulen et al:: Immunophenotyping invasive

breast cancer: paving the road for molecular imaging. BMC Cancer 2012 $12: 240$

\section{Submit your next manuscript to BioMed Central and take full advantage of:}

- Convenient online submission

- Thorough peer review

- No space constraints or color figure charges

- Immediate publication on acceptance

- Inclusion in PubMed, CAS, Scopus and Google Scholar

- Research which is freely available for redistribution 